\title{
A power market-based operation support model for sub-daily hydropower regulation practices
}

\author{
Ali Torabi Haghighi*, Faisal Bin Ashraf ${ }^{a}$, Joakim Riml ${ }^{\mathrm{b}}$, Jarkko Koskelac ${ }^{\mathrm{c}}$, Bjørn Kløvea ${ }^{\mathrm{a}}$, Hannu Marttila ${ }^{\mathrm{a}}$
}

${ }^{a}$ Water, Energy and Environmental Engineering Research Unit, PO Box 4300, 90014 University of Oulu, Finland; ali.torabihaghighi@oulu.fi,faisal.ashraf@oulu.fi, hannu.marttila@oulu.fi, bjorn.klove@oulu.fi

${ }^{b}$ Royal Institute of Technology (KTH), Teknikringen 10b, 11428 Stockholm, Sweden; riml@kth.se

${ }^{\mathrm{d}}$ Finnish Environment Institute (SYKE), Latokartanonkaari 11, 00790 Helsinki, jarkko.j.koskela@ymparisto.fi

*Corresponding author at: Water, Energy and Environmental Engineering Research Unit, PO Box 4300, 90014

University of Oulu, Finland. Telephone: +358413699441, E-mail: ali.torabihaghighi@oulu.fi

\section{https://doi.org/10.1016/j.apenergy.2019.113905}

\begin{abstract}
With increasing power production from renewable energy sources, sub-daily variations in energy demand need to be balanced. Today, hydropower is commonly used as balancing power. In this study, we quantified the impact of capacity constraints, in terms of reservoir volume and hydropower capacity, on the potential to comply with instant energy demand. To evaluate the impact, we developed two new metrics, power market impact and system efficiency ratio, which are based on two threshold flow regimes derived from natural flow as lower threshold release and regulated flow (based on hourly energy prices) as upper threshold release. The operation support model comprises 96 different regulation scenarios based on varying combinations of hydropower and reservoir capacities. For each scenario, an hourly water balance was simulated, to obtain the highest complying with upper threshold release based on actual energy demand. We tested the framework on the Kemijoki river with defined thresholds based on the natural flow regime (tributary river Ounasjoki) and the hourly energy price in Finland in 2017, and estimated the impact of regulation on hourly flow regime at the Taivalkoski hydropower station. The annual flow regime impact in 2013, 2014 and 2015 was estimated to be $74 \%, 84 \%$ and $61 \%$, respectively, while the monthly impact varied from $27 \%$ to $100 \%$. Our framework for evaluating interactions between the power market and sub-daily regulation practices is a useful novel tool for sustainable river management and can be easily applied to different rivers and regions and evaluated for different timescales.
\end{abstract}

Keywords: River Regulation, Hydropeaking, Flow regime alteration, Sub-daily variation, Power market, Renewable energy.

Nomenclature

Abbreviations and acronyms

AF

Annual flow $\left(\mathrm{m}^{3}\right)$

AQ

Allocated flow

DCC

Daily contribution coefficient

ELV Max

Maximum water level in reservoir 
ELV $_{\text {Min }}$

Minimum water level in reservoir

ELV $_{\text {Nor }}$

Normal water level in reservoir

HPcap

Hydropower capacity

HPS

Hydropower scale

LTR

Lower threshold release

MCC

Monthly contribution coefficient

mdt

Month, day, time (hour)

MWh

Megawatt hour(s)

ndym

Number of days in month $m$

PMI

Power Market Impact

$\mathrm{Q}_{\text {in }}$

Inflow to reservoir $\left(\mathrm{m}^{3} \mathrm{~s}^{-1}\right)$

$\mathrm{Q}_{\mathrm{hp}}$

Outflow from hydropower $\left(\mathrm{m}^{3} \mathrm{~s}^{-1}\right)$

$\mathrm{Q}_{\mathrm{Sp}}$

Outflow from spillway $\left(\mathrm{m}^{3} \mathrm{~s}^{-1}\right)$

SER

System Efficiency Ratio

TCC

Hourly contribution coefficient

UTR

Upper threshold release

$\mathrm{V}_{\text {Max }}$

Maximum volume in reservoir

$\mathrm{V}_{\text {Min }}$

Minimum volume in reservoir 
Normal volume in reservoir

$\mu$

Mean annual flow $\left(\mathrm{m}^{3} \mathrm{~s}^{-1}\right)$

$\eta$

Efficiency of hydropower

\section{Introduction}

Despite concerns about the feasibility of achieving highly efficient combinations of low-carbon technologies [1], power markets are already changing rapidly to include an increasing share of renewable energy production [2], [3]. Hydropower can act as a buffer for renewable intermittencies and play a supporting role in increasing renewable penetration, without necessarily requiring construction of additional hydropower plants [6]. However, this will require changes in the operating pattern of the hydropower system [4], so increased penetration of variable renewable energy sources in power systems will affect hydropower operating regimes [5]. However, the energywater nexus and stricter environmental restrictions have complex influences on riverine flow patterns, and both will affect hydropower plant operation [7]. Future hydropower regulation practices may also change under a changing climate [8] and due to the economic benefits of reducing greenhouse gas emissions [9].

For a highly renewable energy system to provide a reliable supply, sufficient flexibility is required in the system at short time scales [10], which is currently provided by hydropower. The reliability, flexibility and balancing potential of the hydropower sector is directly linked to changing river regimes [11], [12],13], altering the flow regime more than predicted climate change [14], [15], [16], [17]. Long-term regulation for hydropower generation homogenises river flow dynamics by dampening the natural flow variations [18], but at sub-daily scales it increases flow variations, an effect referred to as hydropeaking [19], [20]. Negative impacts of sub-daily flow alteration may include direct impacts on aquatic organisms [21], [22], a decline in fish habitat quality [23], thermal regime change in the regulated river water [24] and restricted recreational use of the river corridor. The impact of short-term regulation is evident as a drastic increase in downstream river flow variability and ecosystem changes [20], [25]. The impact of dams and hydropower on rivers has been well documented [26], [27], but the impact of hydropeaking is less-well known [28]. To the best of our knowledge, previous studies assessing the impact of hydropeaking on flow regime have mainly focused on rising and falling flow, ramping rate and rapid fluctuations [29], [30]. To assess the impacts more fully, the combined effect of the power market (demand) and regulation practices (supply) on sub-daily flow variations needs to be determined using novel methodologies.

In the Nordic countries, hydropower generation is partly controlled by a common electricity market. Wholesale electricity is traded through the Nord Pool Spot power exchange, which uses Elspot (day-ahead) and Elbas (intraday) to set the market price. In the deregulated power market, hydropower production is bid into the dayahead market [31], [32] and is also used to provide load balancing at intra-day and intra-hour time steps [33]. To maximise the total generation of revenue by providing load balancing at intra-day and intra-hour time steps, operators prefer to release more water through turbines when the price is high (often during peak demand hours) and store water or release less when the price is low (often during low demand hours). The release rate can change at intra-hour time steps, causing hydropeaking. As the share of variable renewable energy sources increases, the role of hydropower as a load balancing source of power also increases [7], since energy production from emerging renewable sources (e.g. wind, sun) varies widely on short scales [34], [35]. This growing demand for balancing energy from hydropower puts pressure on operators to increase hydropeaking in regulated river systems, exerting additional pressure on riverine ecosystems. However, methodology to evaluate dual sub-daily regulation pressures from demand and supply into river systems is lacking.

As regulated river corridors offer many ecosystem services, it is important to properly address the ecological and hydrological impacts of hydropeaking practices. Thus, sustainable river management calls for methodologies to 
quantify hydropeaking and its relationship with power market demands. There is currently a knowledge gap regarding the impacts of the major changes currently affecting the energy industry on hydropower reservoir operation practices. The aim of the present study was therefore to devise a framework and scenario-based modelling approach for assessing and characterising hydropeaking river regimes based on power market demand. Hydropeaking river regimes were simulated using actual intra-day electricity price data and different theoretical regulatory scenarios for varying potential reservoir and hydropower capacity. A novel framework and methodology for estimating interactions between power market demand and actual regulation practices were developed. The methodology was tested on the Kemijoki river, which is one of the most regulated river systems in Finland.

The analysis was performed using a multidisciplinary approach that bridges the fields of power market economics, water resources management and river regime alteration. The novel contributions of the study are that: (a) it introduces two new indices, Power Market Impact (PMI) and System Efficiency Ratio (SER), for sustainable hydropower reservoir management under changing energy supply and demand situation; (b) it quantifies the impact of capacity constraints (including reservoir volume and hydropower capacity) on sub-daily flow regime alteration of rivers to comply with the instant energy demand change; and (c) it presents and tests the first holistic methodology to evaluate hydropower reservoir management in the Nordic power market, which is rapidly changing due to growing demand for green energy and a decentralised energy systems market. Our approach can be used to quantify the impact of the power market on hydrological and consequently riverine ecological processes, and can help decision makers resolve the conflict between different stakeholders involved in energy, water and environmental governance.

\section{Material and methods}

\subsection{Flow regime thresholds}

Hydropeaking is a type of river flow regulation that involves frequent release of water over short periods to generate energy to meet any short-term changes in energy demand. As the short-term fluctuations in flow caused by hydropeaking can be assumed to be greater than those in unregulated flow, in our novel approach we set two thresholds to encompass these variations. The flow released from hydropower varies between these two thresholds, where the lower threshold serves as a proxy for the natural flow regime and the upper threshold is defined based on operating policy (here the power market). Natural hourly flow regime was chosen to serve as the lower threshold release (LTR). Its value can be generated from river flow in pristine counterparts or pre-regulated conditions (in the example presented here, we used flow in the Ounasjoki river, a pristine tributary of the Kemijoki river). The upper threshold (here due to hydropeaking) is calculated based on the fluctuating hourly energy prices and assumes severely regulated conditions, which include a combination of large storage reservoir and large hydropower capacity resulting in potential for highly flexible operation. To calculate the upper threshold, we designed an hourly allocation plan in which annual flow release is proportional to its hourly price for each single hour of the year:

$$
A Q_{m d t}=C T_{m d t} \times A F
$$

where $\mathrm{AQ}_{\mathrm{mdt}}$ is the hourly allocated flow $\left(\mathrm{m}^{3}\right)$ for hydropower generation, $\mathrm{AF}$ is volume of annual flow $\left(\mathrm{m}^{3}\right)$ and $\mathrm{CT}_{\text {mdt }}$ (combination of three other coefficients) is hourly contribution coefficient for a specific month (m), day (d) and hour $(\mathrm{t})$ according to:

$$
C T_{m d t}=M C C_{m} \times D C C_{m d} \times T C C_{m d t}
$$

The term $\mathrm{MCC}_{\mathrm{m}}$ in Eq. (2) is monthly (January-December = 1-12) contribution coefficient, calculated as:

$$
\left\{\begin{array}{c}
M C C_{m}=\frac{\sum_{d=1}^{d=n d y m} \sum_{t=1}^{t=24} P_{m d t}}{\sum_{m=1}^{m=12} \sum_{d=1}^{d=n d y m} \sum_{t=1}^{t=24} P_{m d t}} \\
\sum_{m=1}^{m=12} M C C_{m}=1
\end{array}\right.
$$


where $\mathrm{P}_{\mathrm{mdt}}$ is the price of one MGWh of energy during month $m$, day $d$ and time $t$ and ndym is the number of days in month $m$.

The term $\mathrm{DCC}_{\mathrm{md}}$ in Eq. (2) is daily contribution coefficient, calculated as:

$$
\text { for each day: } \begin{aligned}
D C C_{m d}= & \frac{\sum_{t=1}^{t=24} P_{m d t}}{\sum_{d=1}^{d=n_{m o n t h}} \sum_{t=1}^{t=24} P_{m d t}} \\
& \sum_{d=1}^{d=n_{m o n t h}} D C C_{m d}=1
\end{aligned}
$$

The term $\mathrm{TCC}_{\mathrm{mdt}}$ in Eq. (2) is the hourly contribution factor, calculated as:

$$
\begin{gathered}
T C C_{m d t}=\frac{P_{m d t}}{\sum_{h=1}^{h=24} P_{m d t}} \\
\sum_{t=1}^{t=24} T C C_{m d t}=1
\end{gathered}
$$

A regulation scenario where allocated water release from the reservoir for hydropower generation is strictly based on Eq. (1) will theoretically generate energy according to hourly power market demand. This release is referred to hereafter as upper threshold release (UTR) for the regulation strategy. Here, UTR was calculated based on electricity prices, as these data were available for the study area, but it can also be calculated based on the balancing market and frequency control market (ignored in this study). In addition, UTR can be viewed as a favoured or initial pattern for releasing water and it can be calibrated by considering any other constraints imposed by water authorities and/or other stakeholders. In this work, we focused on two constraints only, a combination of reservoir volume and hydropower capacity.

As the LTR is derived from natural flow regime, it shows seasonal natural flow variability. During April-June, the natural flow in the Nordic region is dominated by snowmelt season, resulting in peak flow in that period. The UTR is based on the power market, which leads to more homogenised long-term flow (less monthly variation in the outflow). To comply with the energy demand (LTR), discharge during the high-flow season (i.e. April-June in the study area) is stored and released during the low-flow season.

\subsection{Designing different regulation practices}

Releasing flow based on UTR is admittedly complicated, if not impossible. Because of limitations in hydropower capacity and reservoir storage, the hourly flow release will fall between the upper and lower thresholds. To estimate the possible impact of hydropeaking on flow regime, we simulated hydropower operation using different constraints, expressed as a combination of reservoir volume and hydropower capacity. We developed 96 scenarios to cover a wide range of constraints resulting in regulated flow regimes between the upper and lower thresholds. Each scenario involved a certain reservoir size ( 8 options) and a certain hydropower generation capacity (12 options). By developing these scenarios, many intermediate flow regime levels (due to hydropeaking) that fall between natural flow regime and UTR were covered.

In these generic scenarios, a dam $15 \mathrm{~m}$ high and equipped with varying hydropower capacity was assumed. A spillway was assumed to be located at an elevation of $10.0 \mathrm{~m}$ (normal water level) and the minimum water level for operating hydropower was assumed to be $5.0 \mathrm{~m}$. Hence, any water level between 5 and $15 \mathrm{~m}$ would be available for power production. This assumption (height) was made based on the common geometry of rivers in Finland, where the landscape is characterised by flat topography and lack of narrow, deep valleys and is thus not suited for 
construction of tall dams. However, in future applications of our framework, these assumptions can be changed to match in situ conditions in other regions.

To make the flow from rivers of varying sizes comparable, we scaled the hourly time series of flow data by dividing each hourly flow value by annual mean flow of the time series:

$$
E Q_{t}=\frac{Q_{t}}{\mu}
$$

where $\mathrm{EQ}_{\mathrm{t}}\left(\mathrm{m}^{3} \mathrm{~s}^{-1}\right)$ is the scaled hourly flow, $\mathrm{Q}_{\mathrm{t}}\left(\mathrm{m}^{3} \mathrm{~s}^{-1}\right)$ is the hourly flow value at time $t$ and $\mu$ is mean annual flow $\left(\mathrm{m}^{3} \mathrm{~s}^{-1}\right)$.

After scaling, we obtained an hourly time series, with $1 \mathrm{~m}^{3} \mathrm{~s}^{-1}$ (or 31.5 million $\mathrm{m}^{3}$ per year) as mean flow. This scaled time series still captures all the hourly flow variations in the parent time series data. Taking into account the scaled mean flow of $1.0 \mathrm{~m}^{3} \mathrm{~s}^{-1}$ and $10 \mathrm{~m}$ as arbitrary mean potential head over the hydropower, the mean energy production (potential for energy generation), hereafter referred to as hydropower scale (HPS), would be $353 \mathrm{MWh}$ according to:

$$
H P=3600 \times \eta \gamma Q h
$$

where HP (W) is the amount of energy generated, $\mathrm{Q}\left(\mathrm{m}^{3} \mathrm{~s}^{-1}\right)$ is flow release from hydropower, $\mathrm{h}(\mathrm{m})$ is the water head over the hydropower, $\eta$ is efficiency of hydropower (here $=0.9$ ) and $\gamma$ is the unit weight of water.

Based on this mean energy production (HPS $=353 \mathrm{MWh}$ ), we considered 12 different hydropower options covering electricity generation within the range $0-2648 \mathrm{MWh}$. This means that river regulation practices were simulated for no hydropower, very small hydropower capacity (10\% of HPS) and up to large hydropower capacity ( $750 \%$ of HPS). These hydropower options were combined with eight varying reservoir storage volume values at normal water level (range 0.03 to 100 million $\mathrm{m}^{3}$ ). This range of reservoir size covers all reservoirs from very small (volume $<1 \%$ of annual flow (AF)) to large (volume $310 \%$ of AF). Combining the 12 options of hydropower capacities with the eight reservoir volume options gave 96 scenarios. Increasing reservoir size and hydropower generation capacity leads to increased capability for regulating flow approaching UTR, while decreasing reservoir size and hydropower generation capacity constrains regulation closer to the lower threshold, i.e. natural flow conditions.

\subsection{Release simulations for different scenarios}

Hourly water balance equation (Eq. (8)) was used to simulate water release as close as possible to UTR for each of the scenarios designed (Fig. 1):

$V_{t+1}=V_{t}+Q_{i n}-Q_{h p}-Q_{s p}$

where $\mathrm{V}_{\mathrm{t}+1}$ and $\mathrm{V}_{\mathrm{t}}\left(\mathrm{m}^{3}\right)$ are volume of the reservoir at time $t+1$ and $t$ (hour), Qin $\left(\mathrm{m}^{3} \mathrm{~s}^{-1}\right)$ is inflow to the reservoir (between $\mathrm{t}$ and $\mathrm{t}+1), \mathrm{Q}_{\mathrm{hp}}\left(\mathrm{m}^{3} \mathrm{~s}^{-1}\right)$ is outflow from the hydropower unit (between $\mathrm{t}$ and $\mathrm{t}+1$ ), which is released to produce electricity (controlled outflow), and $\mathrm{Q}_{\mathrm{sp}}\left(\mathrm{m}^{3} \mathrm{~s}^{-1}\right.$ ) is uncontrolled outflow from the spillway (between $\mathrm{t}$ and $\mathrm{t}+1$ ), which occurs when the water level is higher than the normal water level in the reservoir (Fig. 1a). In fact, in each time step (single hour), the simulation process tries releasing water in order to approach UTR (as near as possible, the first priority for release), but the release rate depends on available water in the reservoir, head of water and the capacity for hydropower generation.

In each time step, the simulated reservoir volume varies between $\mathrm{V}_{\min }$ and $\mathrm{V}_{\max }$, characterising variations between the maximum (Elv $\left.v_{\text {Max }}\right)$ and minimum (Elv $\left.v_{\text {Min }}\right)$ water level. Between these two limits, we have normal volume $\left(\mathrm{V}_{\text {Nor }}\right)$ and normal water level (Elv $\left.v_{\text {Nor }}\right)$. In the simulation process, we assumed the relationship between volume and water level to be linear and to vary between minimum volume (related to Elv $v_{\text {Min }}=5 \mathrm{~m}$ ) and maximum volume (related to $\left.\mathrm{El}_{\mathrm{Max}}=15 \mathrm{~m}\right)$. 


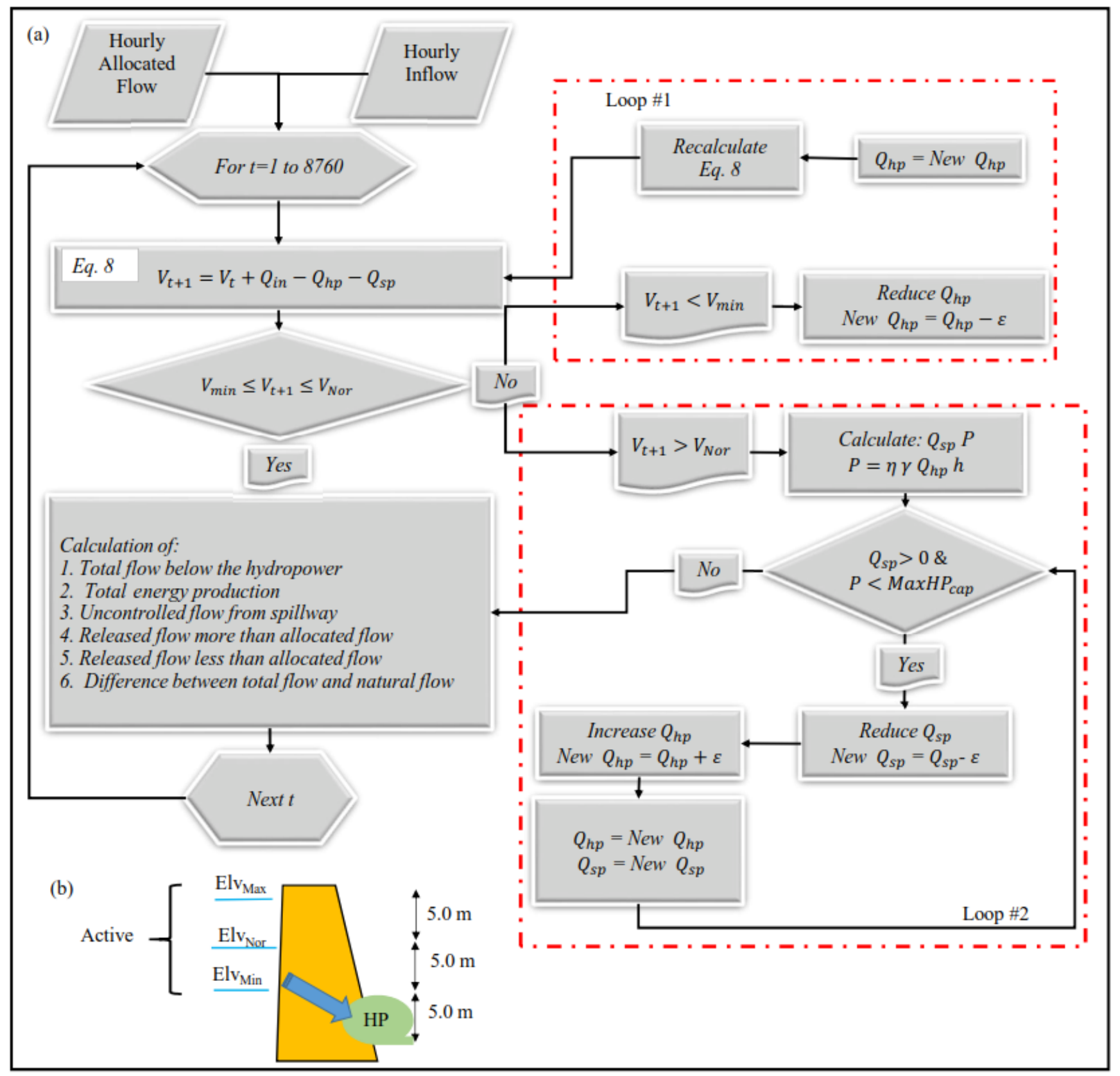

Figure 1. Calculating different outflows from the hydropower system. (a) Flowchart for hourly water balance simulation in the reservoir and hydropower system. (b) Schematic diagram of dam and hydropower and different water level assumptions used in simulations.

Hourly flow release from the reservoir (Qhp and Qsp) is decided by the following conditions (Fig. 1):

- If the water level in the reservoir is between Elv Min $_{\text {and Elv }}$, flow release will be according to UTR (upper threshold) (Fig. 1). In this case, energy production between the time steps $t$ and $t+1$ is calculated as:

$$
A H P_{m d t}=3600 \times A Q_{m d t} \eta \gamma h
$$


where $\mathrm{AHP}_{\mathrm{mdt}}(\mathrm{W})$ is the amount of energy produced according to the allocated flow $\left(A Q_{m d t}\right)$ for the specific time $(1 \leq \mathrm{t} \leq 24)$ on a specific day $(1 \leq \mathrm{d} \leq 31$ (or $30,29,28))$ during a specific month $(1 \leq \mathrm{m} \leq 12), \eta$ is efficiency of hydropower, $\mathrm{h}$ is head over the hydropower and $\gamma$ is the unit weight of water.

- If the water level at the end of current time step is less than Elv Min, the outflow is reduced by decreasing $\mathrm{Q}_{\mathrm{hp}}$. Decreasing $\mathrm{Q}_{\mathrm{hp}}$ is placed in a loop by reducing $\varepsilon$ (here equal to $0.01 \mathrm{~m}^{3} \mathrm{~s}^{-1}$ ) in each stage and

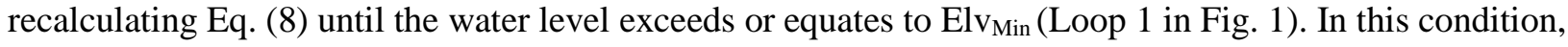
the system is incapable of generating energy according to UTR, due to insufficient inflow or stored water in the reservoir.

- If the water level is higher than $\operatorname{El}_{\text {Nor }}$, additional water will be released through the spillway. To calculate $\mathrm{Q}_{\text {sp }}$, we used the outflow equation for ogee spillways [36]:

$$
Q_{s p}=c h^{3 / 2}
$$

where $\mathrm{h}(\mathrm{m})$ is the difference between water level in the reservoir and Elv $\mathrm{vor}_{\text {, }} \mathrm{c}$ is a spillway coefficient (with a suggested value of 2.1 according to USBR, 1987) and $l(\mathrm{~m})$ is the length of the spillway.

When water level is greater than Elv $\mathrm{v}_{\mathrm{Nor}}$, the model first checks the amount of energy produced (Eq. (7)), because as a default condition the outflow will be considered according to UTR (upper threshold of flow release). If the amount of energy generated is smaller than the hydropower capacity, the full capacity for hydropower production will be utilised then there will be outflow from the spillway (Loop 2 in Fig. 1a). In this condition, due to the limitation of reservoir capacity, the system will generate more energy (second priority for release) than in the allocated plan, so the flow release through the hydropower unit will exceed UTR (new $\mathrm{Q}_{\mathrm{hp}}=A Q_{m d t}+\mathrm{Q}_{\mathrm{Ehp}}$ ) at time $\mathrm{t}:$

$$
\begin{aligned}
& H P_{a l l}=3600 \times Q_{m d t} \eta \gamma h \\
& P Q_{E h p}=\frac{H P_{C a p}-H P_{A l l}}{\eta \gamma h \times 3600} \\
& \text { If } P_{E h p} \geq Q_{s p} \text { then } Q_{E h p}=Q_{s p} \text { and } Q_{s p}=0 \\
& \text { If } P_{E h p}<Q_{s p} \text { then } Q_{E h p}=P Q_{E h p} \text { and } Q_{s p}=Q_{s p}-P_{E s p}
\end{aligned}
$$

where $\mathrm{HP}_{\text {all }}$ is the amount of energy produced by the allocated flow $\left(A Q_{m d t \mathrm{p}}\right), \mathrm{HP}_{\text {cap }}$ is the hydropower capacity MWh and $\mathrm{PQ}_{\mathrm{Ehp}}$ is the extra potential discharge for hydropower at time $t$. Therefore, in each simulated scenario, there are three outflow priority levels (order 1-3). The first-priority release is to comply with the UTR and can be

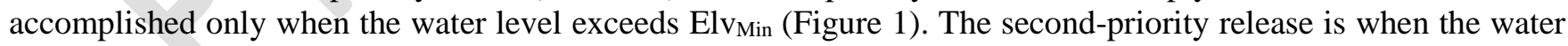
level is higher than Elv ${ }_{\text {Nor }}$ and the hydropower capacity is not fully served for UTR (Figure 1, loop \#2). The thirdpriority release is when the water level is higher than Elv Nor $_{\text {and }}$ water from the spillway is utilised to fully exploit the hydropower generation capacity (Figure 1, loop \#2).

\subsection{Power Market Impact (PMI) and System Efficiency Ratio (SER)}

To estimate the impact of each scenario on flow regime, we developed a Power Market Impact (PMI) index, the value of which varies between 0 and 1 : 
$\mathrm{PMI}==\frac{\sum_{t=S h}^{t=E h} a b s\left(N_{f_{t}}-I_{f_{t}}\right)}{\left.\sum_{t=S h}^{t=E h} a b s\left(N_{f_{t}}-A_{f_{t}}\right)\right)}$

where $\mathrm{I}_{\mathrm{f}_{\mathrm{t}}}$ is the current regulated discharge downstream of hydropower plant in the river analysed in each scenario, $\mathrm{N}_{\mathrm{f}_{\mathrm{t}}}$ is the scaled value of natural flow upstream in the river or lower threshold, $\mathrm{A}_{\mathrm{f}_{\mathrm{t}}}$ is the allocated flow and $\mathrm{Sh}$ and Eh are the start and end hours in the period for which PMI is being calculated. For example, to calculate annual PMI, Sh $=1$ and Eh $=8760$ (365x24), while to calculate PMI for January, Sh $=1$ and Eh $=744$ (31 x 24).

Full compliance with the allocated flow (or UTR, which is obtained from Eq. (1)) is the ideal scenario in economic terms, but achieving this is severely dependent on the system characteristics (reservoir volume and hydropower). Regulated outflow regime usually falls between the natural flow regime and the UTR, where an outflow regime closer to natural flow indicates lower environmental impact and a flow regime approaching UTR indicates higher environmental impact. The intensity of impact is dependent on the volume of the reservoir and hydropower production capacity. According to Eq. (13), in natural conditions the numerator is 0 (as $\mathrm{Nft}=\mathrm{Ift}$ ) and consequently the impact will be zero (PMI=0). When the release flow is fully compliant with allocated flow (or UTR), the numerator and denominator are equal $\left(\right.$ as $\left.\mathrm{Ift}=\mathrm{A}_{\mathrm{ft}}\right)$, which leads to the maximum impact $(\mathrm{PMI}=1)$.

The efficiency of different scenarios to use water for energy production is quantified as the System Efficiency Ratio (SER), which is a function of spillway outflow and total outflow over a certain period:

$\mathrm{SER}=1-\frac{\sum_{t=S h}^{t=E h} V s p_{t}}{\sum_{t=S h}^{t=E h} V_{t}}$

where $\mathrm{V}_{\mathrm{t}}$ and $\mathrm{Vsp}_{\mathrm{t}}$ are volume of total outflow and spillway outflow at time t, respectively, and Sh and Eh are start and end hours in the period for which SER is being calculated. SER varies between 0 and 1, where SER = 1 means all flow passing through hydropower and 0 means the reservoir does not have any hydropower. It must be pointed out that UTR is one state with $\mathrm{SER}=1$.

\subsection{Datasets used and validation of the method}

We used monthly and hourly energy prices based on the Nord Pool Spot power exchange for the year 2017 (data available from Nord Pool's website, https://www.nordpoolgroup.com/) to calculate a representative demand from the power market, which was used in all simulations. As a case study river, we used hourly discharge data for the strongly regulated Kemijoki river (length $550 \mathrm{~km}$, catchment size $50683 \mathrm{~km}^{2}$, mean annual discharge $515 \mathrm{~m}^{3} \mathrm{~s}^{-1}$ ) in Northern Finland [18]. We used our newly developed methodology to characterise the sub-daily regulation regime of the Kemijoki river downstream of Taivalkoski power plant. Regulation of the Kemijoki for hydropower generation started in 1949 and since then a total of 18 plants have been constructed. In addition, two major reservoirs, Porttipahta $\left(1.35 \mathrm{~km}^{3}\right)$ and Lokka $\left(1.46 \mathrm{~km}^{3}\right)$, have been constructed at the headwaters of the Kemijoki (in 1967 and 1981, respectively). Taivalkoski gauging station is below the second last hydropower on the Kemijoki river, so the observed flow at Taivalkoski reflects the impact of 17 hydropower plants across the catchment.

As the main corridor of the Kemijoki river is regulated by several hydropower plants, natural conditions could not be observed. Therefore, to estimate the LTR we used data for its largest unregulated tributary, the Ounasjoki river, at Marraskoski gauging station. The Ounasjoki (mean annual discharge $140 \mathrm{~m}^{3} \mathrm{~s}^{-1}$ ) is approximately $300 \mathrm{~km}$ in length and contributes $27 \%$ of total annual flow in the Kemijoki river basin. Hourly discharge data $\left(\mathrm{m}^{3} \mathrm{~s}^{-1}\right)$ at the Taivalkoski plant and Marraskoski station used in the analysis were obtained from the Finnish Environment Institute (SYKE).

\section{Results}




\subsection{Variation in energy prices over the year and flow regime thresholds}

The main reason for hydropeaking is volatility in hourly energy price. In this study, we estimated UTR using our novel approach, which takes the hourly energy price into account. In 2017, energy prices in Nord Pool Spot were highest in September and lowest in June (Table 1). Based on the aggregated mean weekly price, Wednesday had the highest and Sunday the lowest energy prices (Table 1 and Fig. 2). For all months, Sundays showed the lowest daily price, but the highest daily price varied from month to month (Fig. 2).

Table 1. Mean values of monthly and daily price of energy ( $€ / M W h)$ based on the power market in Finland 2017 (https://www.nordpoolgroup.com/)

\begin{tabular}{|c|c|c|c|c|c|c|c|c|c|c|}
\hline \multirow[b]{2}{*}{ Month } & \multirow[b]{2}{*}{ Mean } & \multicolumn{8}{|c|}{ Mean weekday price } & \multirow[b]{2}{*}{ Min. } \\
\hline & & Sun & Mon & Tue & Wed & Thu & Fri & Sat & Max. & \\
\hline Jan. & 33.29 & 29.44 & 37.37 & 35.72 & 31.26 & 34.05 & 34.52 & 30.02 & 37.37 & 29.44 \\
\hline Feb & 35.07 & 29.78 & 35.95 & 35.99 & 39.93 & 36.63 & 35.98 & 31.23 & 39.93 & 29.78 \\
\hline Mar & 30.67 & 28.09 & 32.13 & 32.53 & 30.52 & 31.40 & 30.91 & 28.91 & 32.53 & 28.09 \\
\hline Apr & 31.40 & 27.45 & 32.25 & 30.72 & 33.52 & 33.61 & 35.66 & 28.35 & 35.66 & 27.45 \\
\hline May & 30.67 & 24.30 & 31.95 & 33.83 & 33.15 & 30.61 & 30.97 & 28.18 & 33.83 & 24.30 \\
\hline Jun & 30.64 & 22.62 & 34.04 & 31.05 & 34.53 & 33.95 & 32.31 & 24.69 & 34.53 & 22.62 \\
\hline Jul & 34.17 & 26.85 & 38.17 & 36.46 & 36.33 & 36.60 & 37.03 & 29.72 & 38.17 & 26.85 \\
\hline Aug & 36.28 & 26.48 & 39.00 & 36.65 & 44.48 & 38.72 & 38.30 & 27.59 & 44.48 & 26.48 \\
\hline Sep & 37.27 & 33.23 & 38.05 & 39.43 & 40.29 & 39.41 & 38.11 & 33.20 & 40.29 & 33.20 \\
\hline Oct & 33.43 & 27.47 & 35.12 & 36.09 & 35.92 & 35.63 & 36.57 & 27.60 & 36.57 & 27.47 \\
\hline Nov & 33.67 & 28.59 & 36.51 & 38.96 & 36.68 & 33.77 & 31.93 & 28.53 & 38.96 & 28.53 \\
\hline Dec & 31.92 & 27.66 & 36.61 & 35.77 & 31.89 & 32.75 & 34.08 & 26.58 & 36.61 & 26.58 \\
\hline Mean & 33.21 & 27.66 & 35.60 & 35.27 & 35.71 & 34.76 & 34.70 & 28.72 & 35.71 & 27.66 \\
\hline Maximum & 37.27 & 33.23 & 39.00 & 39.43 & 44.48 & 39.41 & 38.30 & 33.20 & 44.48 & 33.20 \\
\hline Minimum & 30.64 & 22.62 & 31.95 & 30.72 & 30.52 & 30.61 & 30.91 & 24.69 & 31.95 & 22.62 \\
\hline
\end{tabular}

The hourly variation in energy price was calculated to estimate the monthly, daily and hourly coefficients for the simulations using Eqs. (3)-(5) (Fig. 3). By combining these three coefficients (Eq. (2)), we calculated a coefficient for hourly contribution, which was proportional to the hourly price of energy (Fig. 3d). By considering scaled mean annual discharge of $1 \mathrm{~m}^{3} \mathrm{~s}^{-1}$ and also hourly coefficient (Fig. 3d), the UTR flow regime was defined (Fig. 4d). Finding the LTR is challenging, as most rivers have been regulated and as the hourly natural flow regime is highly dependent on climate conditions (hourly rainfall in general and temperature during snowmelt season) and varies from year to year. To determine the PMI for the scenarios and the case study river (Kemijoki), the scaled (time series divided by mean flow) hourly flow regime in the Ounasjoki river at Marraskoski station was taken as the LTR (Fig. 4). 


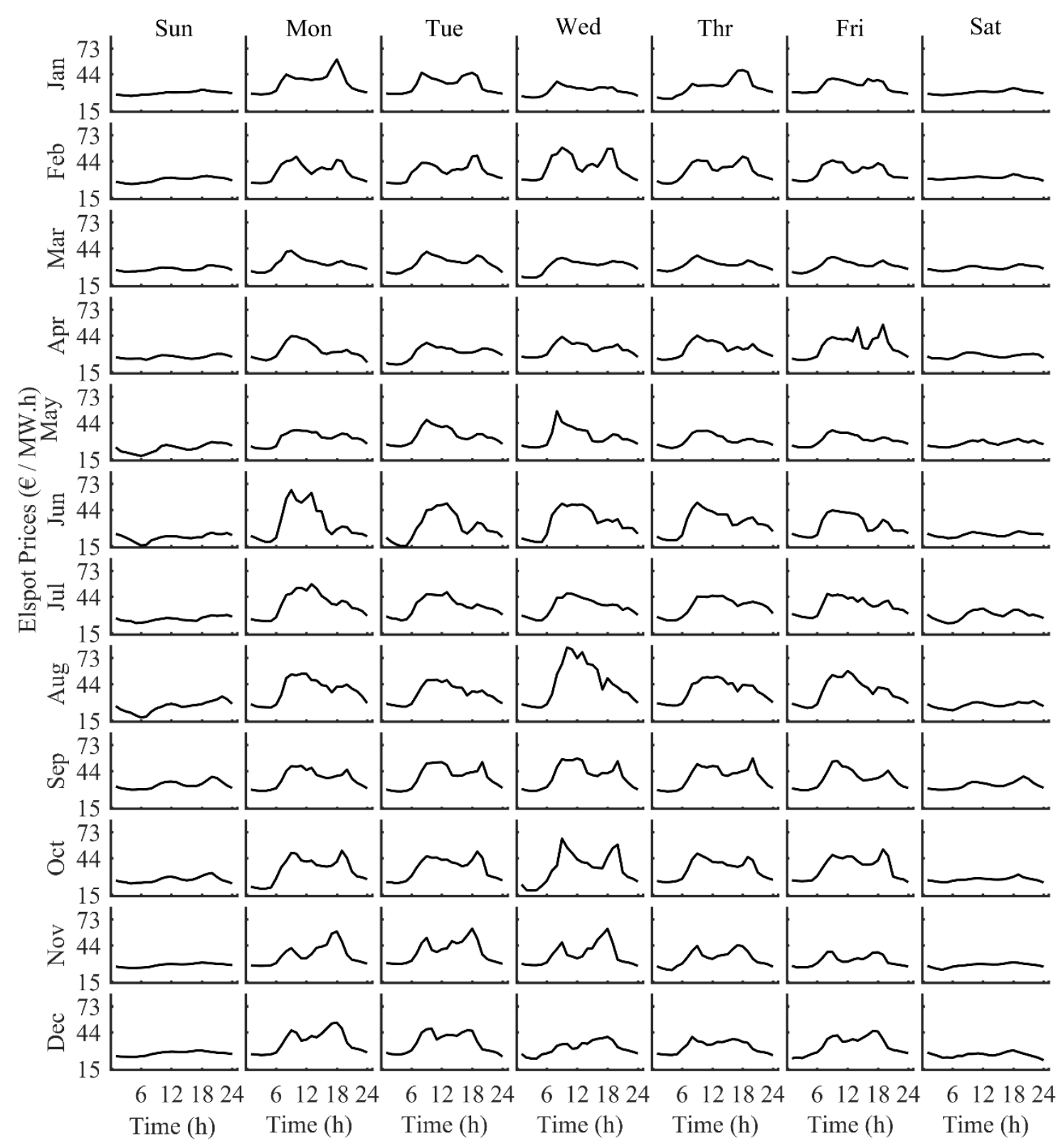

Figure 2. Distribution of hourly energy price averaged over months and weekdays in Finland in 2017. 


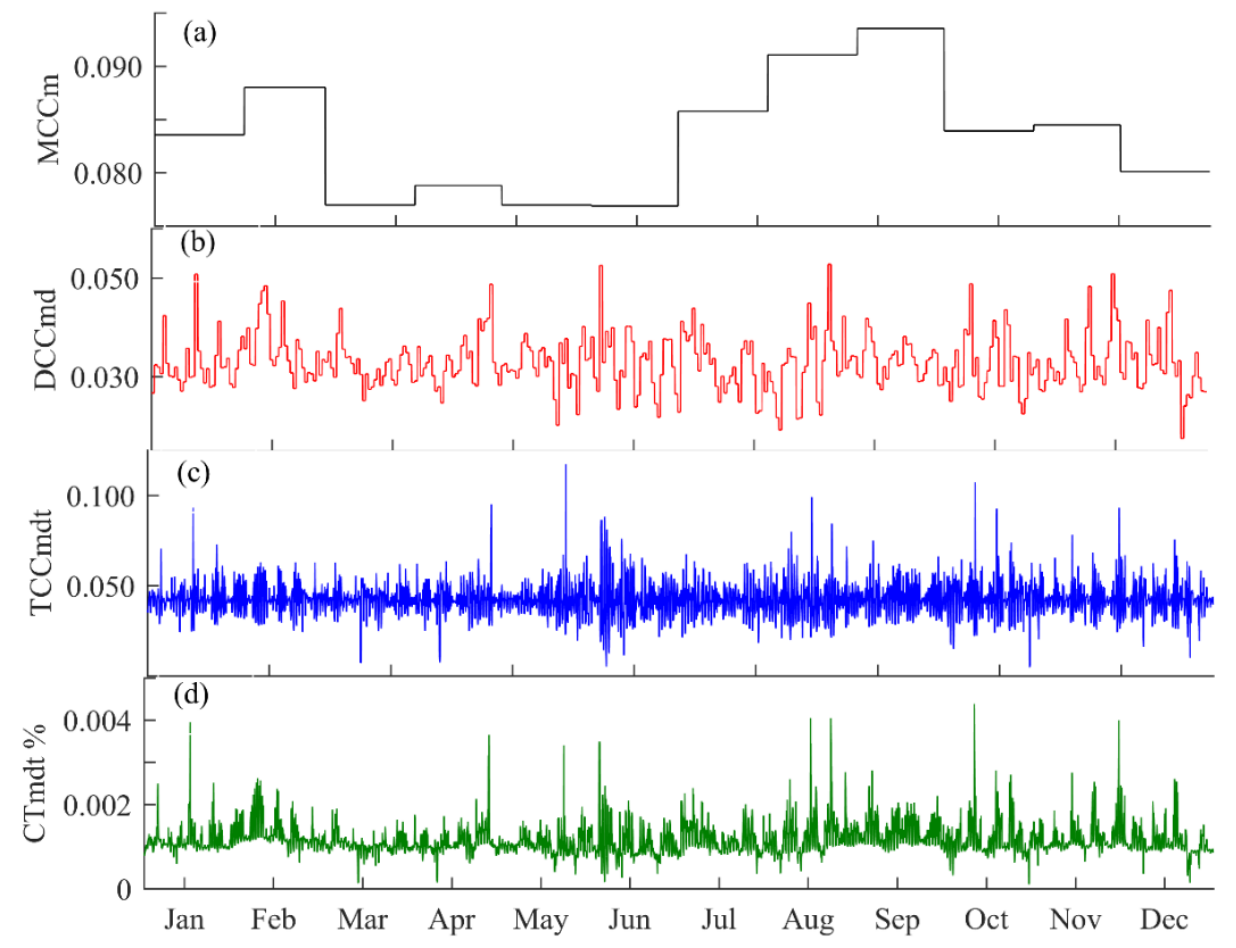

Figure 3. Contribution coefficients. a) Monthly coefficient (MCC), b) daily coefficient (DCC), c) hourly coefficient for each day (TCC) and d) hourly coefficient for the whole year (CTmdt).

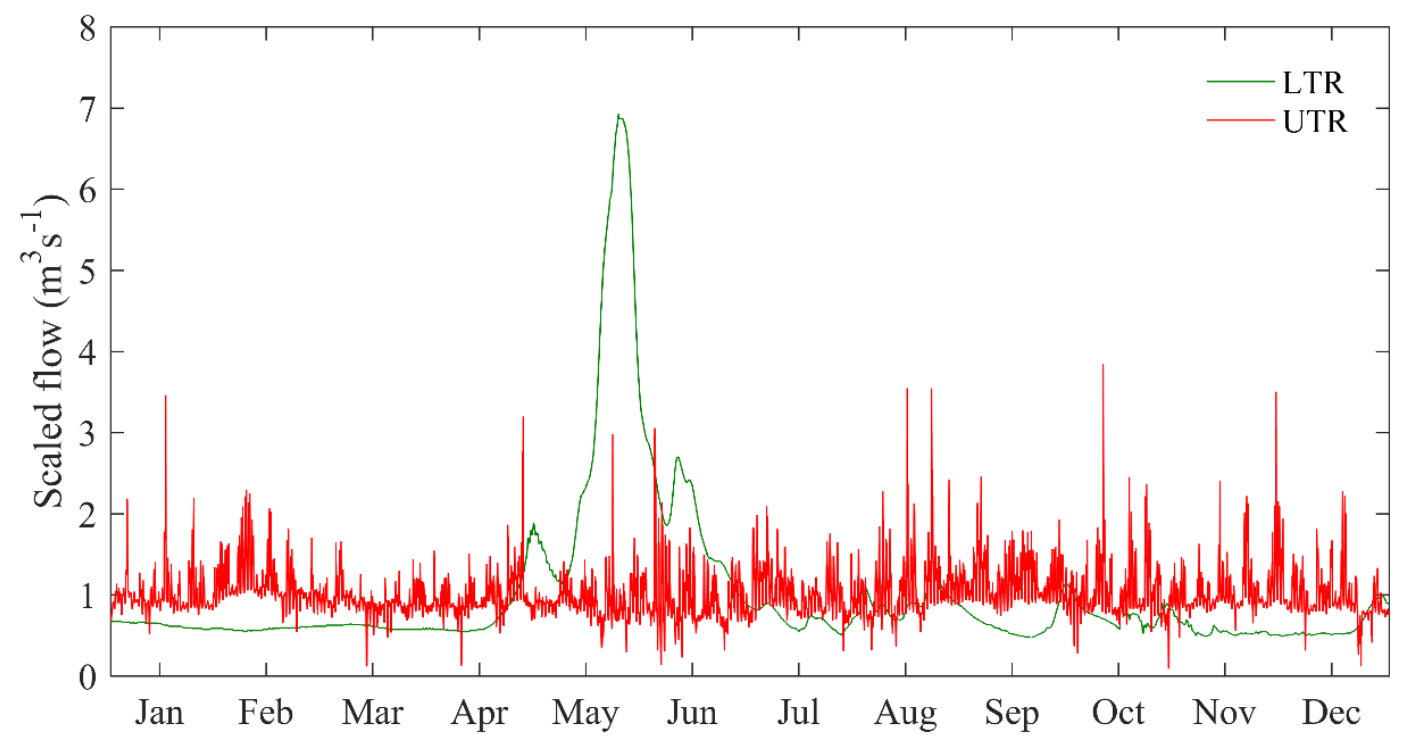

Figure 4. Upper threshold release (UTR) and lower threshold release (LTR) in simulations based on natural flow (scaled flow of the Ounasjoki river at Marraskoski station) and regulated flow to supply power market demand in 2017. 


\subsection{Interaction of power market demand and regulation practices on hydropeaking regime}

Total flow release, including three types of outflow, is shown for five selected scenarios in Fig. 5. The first priority for operation (outflow type) is releasing flow according to UTR when the water level is higher than $\mathrm{V}_{\text {min }}$ (Fig. 5, part 1). The second priority is releasing water through the turbine when the hydropower capacity is not fully served

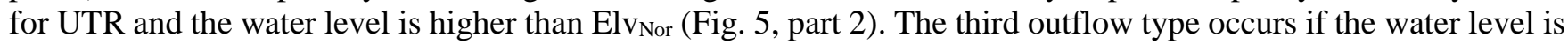
higher than Elv $\mathrm{vor}_{\text {ar }}$ and hydropower production capacity is reached, resulting in water being released through the spillway (Fig. 5, part 3). The sum of these three outflows is the total outflow from the reservoir, which is released to the river as regulated flow (Fig. 5, part 4). Flow release is dependent on inflow to the reservoir, reservoir size, hydropower capacity and demand for energy generation (Fig. 5). The results indicated that in order to comply with the UTR, considerable reservoir volume and hydropower capacity were required (Fig. 5 e1-4). This was most clearly displayed for the scenario using reservoir size $\geq 320 \%$ of AF and hydropower capacity $\geq 750 \%$ of HPS, which resulted in a highly regulated condition for the system and compliance with the UTR (Fig. 5 e1-4). As seen in this scenario, the outflow for the second-priority release (Fig. 5 e2) and spillway flow (Fig. 5 e3) was zero.

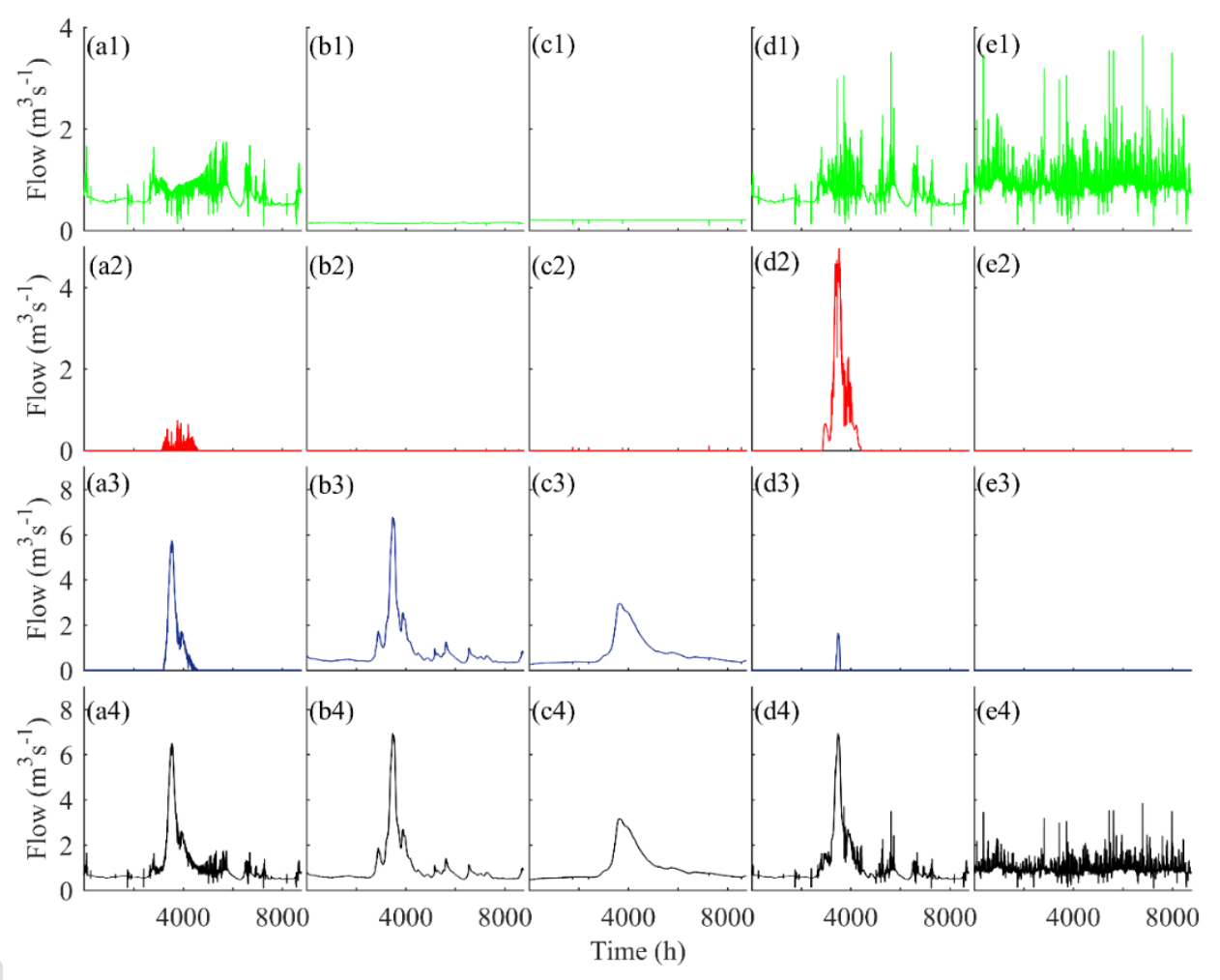

Figure 5. Different types of flow release in different combinations of hydropower capacity and reservoir size. (1) Hydropower flow release according to the upper threshold release (UTR) plan, (2) hydropower flow release outside the UTR plan, (3) uncontrolled flow from the spillway, and (4) total flow release into the river. (a) hydropower capacity at hydropower scale (HPS) and storage at 55\% of annual flow $(A F),(b)$ small reservoir $(4 \% A F)$ and small hydropower capacity (20\% HPS), (c) large reservoir (320\% AF) and small hydropower capacity (20\% HPS), (d) large hydropower capacity (750\% HPS) and small reservoir (4\% AF) and (e) large hydropower capacity (750\% HPS) and large reservoir (320\% AF).

Fully complying with UTR was found to be impossible, regardless of hydropower capacity, in the absence of sufficient reservoir capacity, as seen in the scenario with a combination of small reservoir and large hydropower capacity (Fig. 5d). In this scenario, high hydropower capacity led to more energy production only during the high- 
flow season (outflow to the second-priority release increased), and the amount of extra flow release was not fully served for UTR (Fig. 5 d2). Moreover, having a large reservoir without enough hydropower generation capacity was also insufficient to achieve UTR (Fig. 5c), since in this scenario most of the flow was released through the spillway (Fig. $5 \mathrm{c} 3$ ). The flow regime downstream from this type of reservoir mimicked the outflow of a large lake. The total flow release from a small reservoir (e.g. with volume $4 \%$ of AF) combined with small hydropower capacity (e.g. 20\% of HPS) did not make a significant impact on the natural flow regime (Fig. 5b). In this scenario, total flow release resembled the natural flow condition (Fig. 5 b4) and a considerable amount of flow was released through the spillway (Fig. $5 \mathrm{~b} 3$ ). All four abovementioned scenarios represent extreme combinations of hydropower and reservoir capacities, while in reality the regulation condition falls between these four extreme scenarios (e.g. hydropower capacity equal to HPS and reservoir with volume $0.55 \%$ AF, as in Fig. 5a).

To demonstrate the impact of different regulation capacities, the total outflow for 84 of the 96 simulated scenarios is presented in Fig. 6. In the different scenarios, the hourly flow release was significantly affected by the reservoir volume and the hydropower capacity (Fig. 6). Increasing the hydropower production capacity (moving from top to bottom in Fig. 6) and reservoir volume (moving from left to right in Fig. 6) led to higher potential for regulation. According to the results, in order to comply with the UTR release strategy (red line in Fig. 4), a minimum reservoir capacity of 1.4 times annual inflow (options 6,7 and 8 in Fig. 6) and minimum hydropower generation capacity of 2.6 times HPS (j6-j8, k6-k8 and 16-18 in Fig. 6) would be required.

A large reservoir without a hydropower generation facility (a4-a8 in Fig. 6) or with small hydropower generation capacity (b5-e8 in Fig. 6) functioned as a lake and changed hourly flow regime due to routing the hourly flow in the reservoir. The impact of small reservoirs on flow regime was insignificant (a1-11 in Fig. 6) and flow release from the system was similar to the natural flow (green line in Fig. 4).

\subsection{Power Market Impact (PMI) and System Efficiency Ratio (SER)}

In scenarios with hydropower capacity lower than HPS, annual PMI was completely dependent on reservoir size and the highest PMI was 0.65 for the scenario with reservoir volume $\geq 30 \%$ of AF (Fig. 7a). In scenarios with hydropower capacity exceeding HPS, PMI was found to be independent of hydropower generation capacity and, for a given reservoir volume, PMI was constant (Fig. 7a). Moreover, in all scenarios with reservoir capacity $>30 \%$ of AF and HP/HPS >1, PMI was found to be 1. Consequently, the maximum impact on hourly flow regime occurred due to any combination of: i) hydropower capacity $>1$ HPS and ii) reservoir capacity $\geq 30 \%$ of AF. Other combinations of hydropower and reservoir size in the absence of one of these two conditions resulted in an impact ranging from zero to 99\% (Fig. 7a). Smaller reservoirs, even when associated with considerable hydropower plants, showed lower PMI (Fig. 7a). The highest PMI obtained for the smallest reservoir size analysed (storage: $0.01 \mathrm{AF}$ ) was less than $10 \%$ (Fig. 7a). 


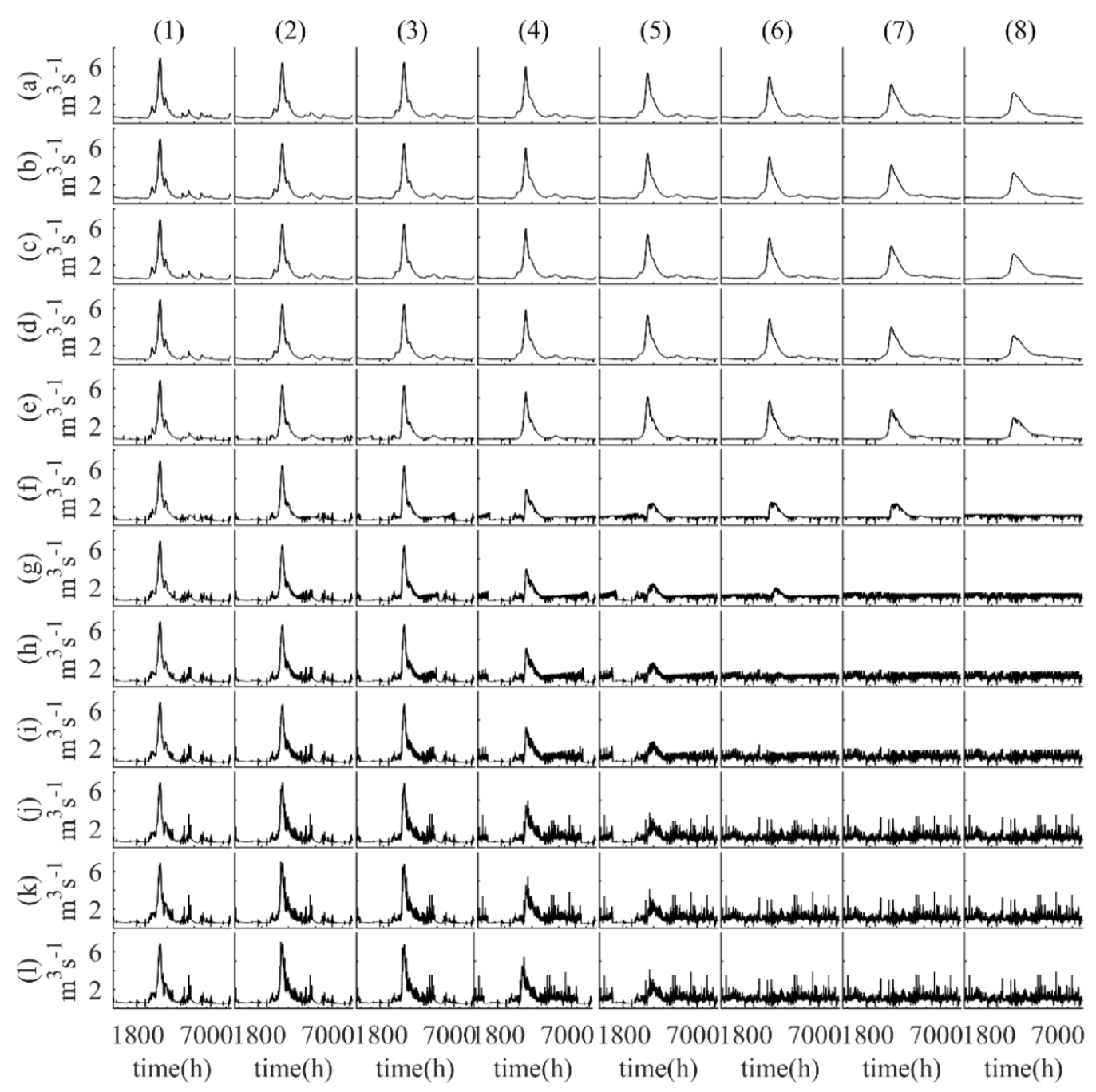

Figure 6. Hourly flow regime below a combination of different hydropower capacity and reservoir sizes. (a) to (l) represent hydropower capacity as 0, 0.1, 0.2, 0.4, 0.6, 0.8, 1.0, 1.2, 1.4, 2.6, 4.5 and 7.5 times hydropower scale (HPS), respectively. (1) to (8) represent reservoir size (volume) as 0.001,0.02, 0.03, 0.10, 0.2, 0.30, 1, and 3.2 times annual flow $(A F)$, respectively.

Increasing the hydropower capacity led to a decrease in the total volume of spillage, and thus an increase in the annual SER (Fig. 7b). SER was different only for scenarios with small hydropower capacity (<1 HPS) (Fig. 7b). For small reservoirs, not even large hydropower capacity (e.g. 750\% of HPS) was sufficient to convey all water through the turbine (Fig. 7b). To utilise all the flow to produce hydropower (SER=1), 100\%, 30\%, 20\% and 10\% of AF storage capacity equipped with $100 \%, 140 \%, 300 \%$ and $750 \%$ of HPS, respectively, would be required (Fig. 7b). In other scenarios, some part of flow remained unutilised and was released through the spillway (Fig. 7b).

The annual flow regime impact downstream of Taivalkoski hydropower plant on the Kemijoki river due to hourly energy production (PMI) during 2013, 2014 and 2015 was estimated to be 0.74, 0.84 and 0.61, respectively (Fig. 8 a2-c2). The intra-annual variability clearly showed the impact on natural flow regime of PMI fluctuation (Fig. 8b). Moreover, the monthly impact displayed high variability, ranging from 0.27 to 1.00 in different months (Fig. 8b). Different PMI values were obtained for different years, showing clearly the impact of natural flow regime on PMI fluctuations (Fig. 8b). 


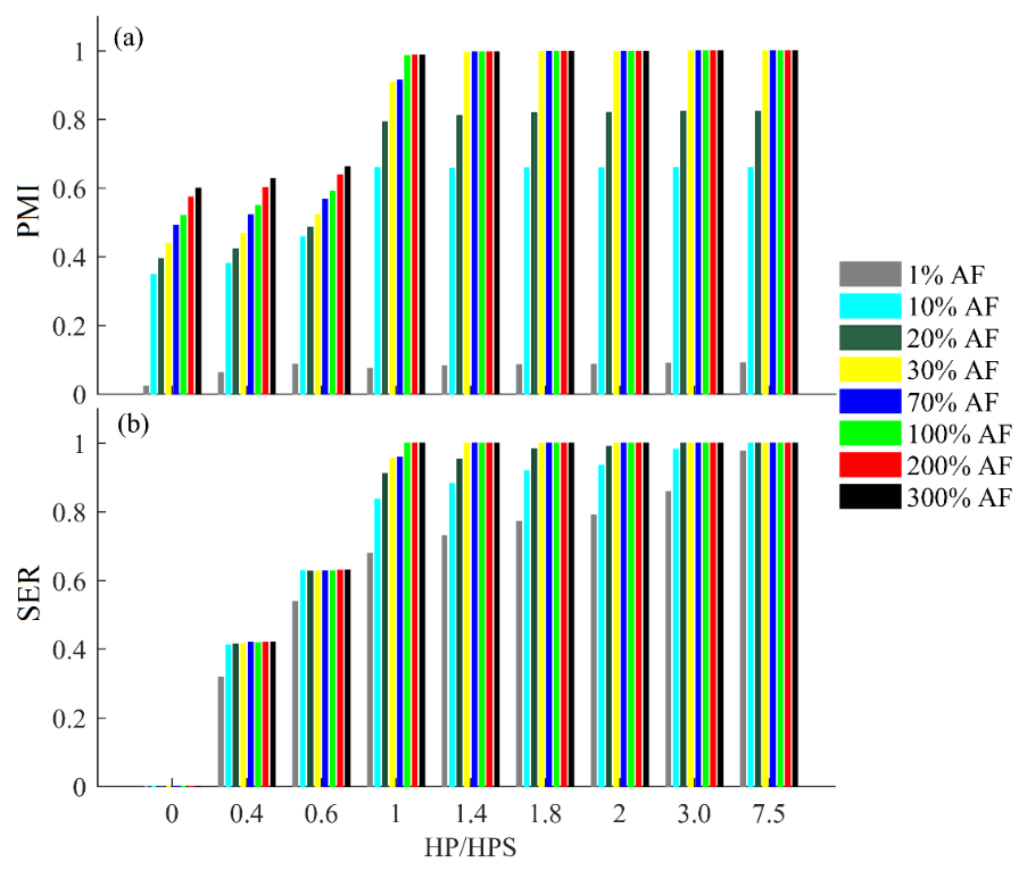

Figure 7. Annual a) Power Market Impact (PMI) and b) System Efficiency Ratio (SER) for different combinations of hydropower/hydropower scale (HP/HPS) and reservoir capacity (fraction of annual flow (AF)).
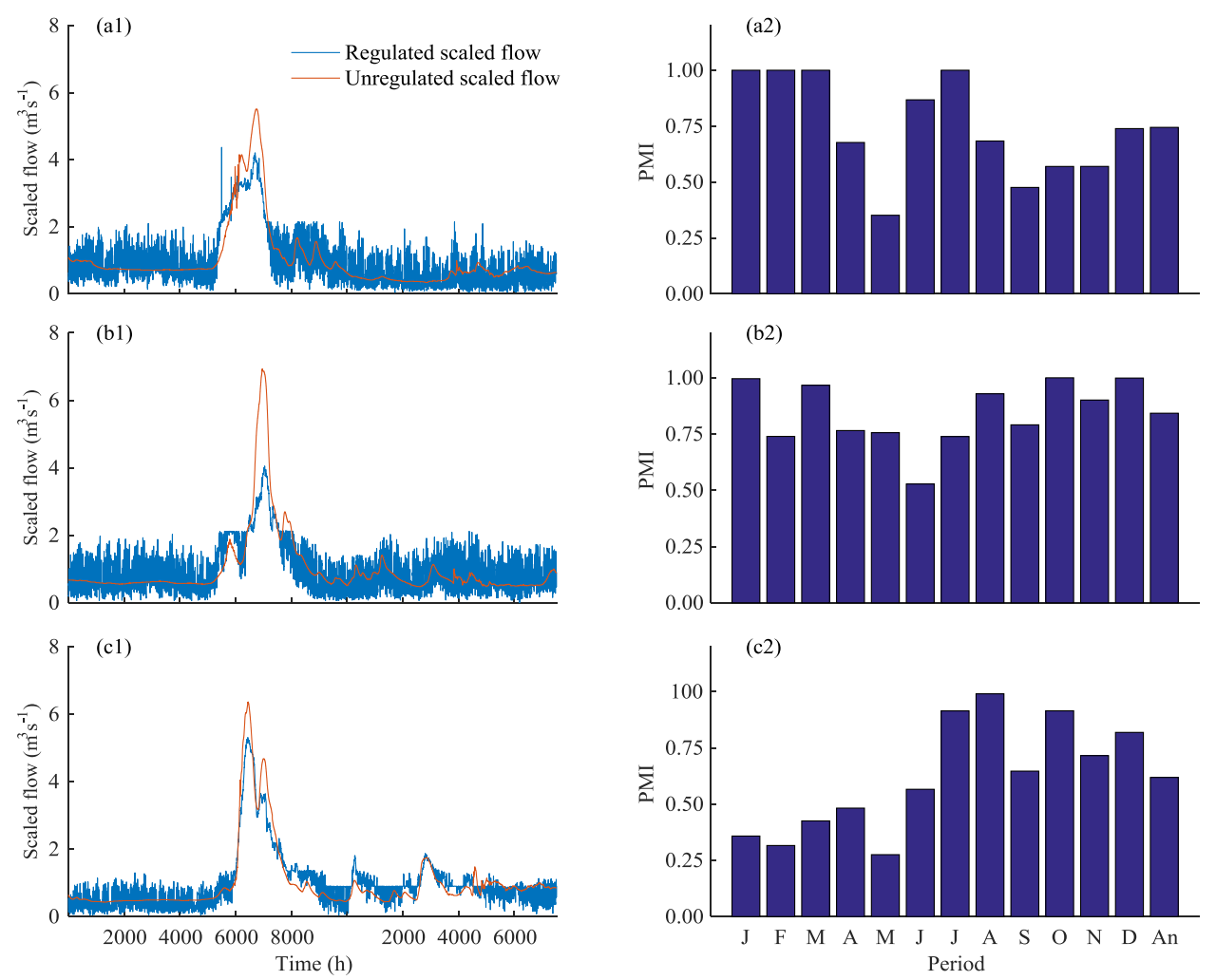

Figure 8. Regulated and unregulated scaled flow regime in the Kemijoki river and Power Market Impact in (a) 2013, (b) 2014 and (c) 2015, where J-...-D means January - .... -December and An is the annual value. 


\section{Discussion}

Previous studies analysing the impact of hydropower management strategies and regulation practices on flow regimes have mostly focused on annual, monthly and daily hydrological alterations [12], [13], [37]. With greater variation in hourly energy demand and prices, the need to use flexible hydropower to balance energy production is increasing. These new regulation strategies exert pressures on riverine ecosystems, particularly impacting the ecological and hydrological functioning. Understanding drivers and causes of sub-daily alterations in hydrological conditions would improve management and aid impact assessment of flow regime changes. Moreover, different system capacities (combination of reservoir size and hydropower capacity) have different possibilities to comply with sub-daily regulation practices, such as instantly following the power market, and thus impact the flow regime differently. Estimation of hourly water balance in a novel method developed in this study allowed us to address changes in sub-daily flow regime and investigate how hydropower system capacities constrain the possibility to produce the highest energy production according to a pre-defined plan.

The method developed and tested in this study can be used to determine the effect of intra-daily variation and power market on regulated river flow regimes. Using actual hourly energy prices together with observed hourly discharge data from regulated and unregulated river systems, we were able to quantify the impact of hydropeaking caused by power market demand. A novel feature of the method is that it considers two threshold releases, based on varying energy prices (UTR) and natural flow (LTR), to quantify the PMI on hourly flow regimes by comparing the altered (regulated) flow of each river with its natural flow. The UTR is defined by several flow coefficients, which are formulated from actual hourly power market exchange and demands, while the LTR is based on natural hourly flow patterns. Using scaled discharge data in the simulation process enables comparison between different types of regulation capacities (reservoir size and hydropower capacity). Moreover, the method can be used to estimate hourly flow regime caused by energy price variations and demand from the power market.

We used the two new metrics developed here, PMI and SER, to find the minimum requirement for complying with a specific regulation strategy. This revealed that, for example, at least $100 \%, 30 \%, 20 \%$ and $10 \%$ of AF reservoir volume, equipped with $100 \%, 140 \%, 300 \%$ and $750 \%$ of HPS hydropower capacity, respectively, was needed in order to follow the allocated release plan and comply with UTR. It should be pointed out that UTR is a specific fully regulated condition in which the flow passing through the hydropower turbines in each time step is based on hourly energy price according to the market (in addition to $S E R=1, P M I=1$ ). The method can be used for different periods by selecting appropriate start and end hours in Eqs. (13) and (14), and can also be used for different time scales (monthly or annually) than those adopted here. Thus it could cover certain periods important e.g. for fish spawning, fish migration or human recreation. In addition, any regulation plan could be used (in theory) as the upper threshold to estimate the impact of any desired operation policy on any desired time scale. Our framework can thus be adjusted to any particular situation and conditions, and used to evaluate pressures from power market demand or to calculate the impact of hourly flow regulation practices.

In our case study river, the Kemijoki, the minimum requirement to achieve UTR was found to be a hydropower capacity equal to $1.40 \%$ of HPS and a reservoir volume that was $32 \%$ of AF. The estimated annual PMI ranged from 0.61 to 0.84 , indicating that sub-daily or hourly flow regimes in the Kemijoki are strongly controlled by power market demand and variation. Monthly PMI values showed how the power market altered the flow regime in different months. It should be noted that the impact values obtained in this study only refer to hydrological change, and no consideration was made of any specific ecological or environmental target. However, if specific flow regimes were defined representing low, incipient, moderate and severe conditions for an ecological event (e.g. the salmonid life cycle), then the PMI could be calculated for any of these flow regimes and an impact scale for that ecological event could be determined. By calculating the PMI for regulated flow in the river, the level of impact on the ecological event due to regulation could then be quantified and the monthly distribution of PMI (Fig. 8) could be linked to varying seasonal ecological or recreational conditions in the river. The method could thus be used for operational support and impact assessment in different seasons and conditions.

In addition to varying prices on the power market, regulated flow pattern is also related to the natural flow regime of a river. Different monthly values of PMI in three different years illustrated this (Fig. 8 a2-c2), as natural flow was the only changing variable in those three years. However, as the outflow of the Kemijoki river is the total 
outflow, and not categorised separately as spillway and hydropower outflow, an absolute SER value for the Kemijoki could not be calculated.

Considering scaled flow and using the HPS concept can help estimate the requirement to achieve different levels of regulation, as shown by the simulation results in section 3.2. Estimating the requirement can help in design and decision making to address river water management issues. Based on the mean annual flow in the Kemijoki, the minimum requirement for complying with UTR is a reservoir with at least $5.2 \mathrm{~km}^{3}$ and installed minimum 495 GWh hydropower capacity (assuming $10 \mathrm{~m}$ head). The active volume capacity of reservoirs in the whole river system is currently less than the minimum value. However, considering that the Kemijoki is already highly regulated, achieving UTR in practice is not possible. Thus, it is not economically feasible to have a fully regulated system, especially when the river corridor has many other functions and ecosystem services to offer [38].

Our novel framework is recommended for evaluating the current hydropeaking status in regulated river systems and its relation to the power market. The method allows for direct comparison of power market demand and flow regime variations, and can thus be an efficient tool for sustainable river management balancing different demands and drivers. This is highly important, since in future more flexible energy sources such as hydropower will be needed to balance sudden production changes in distributed energy production [39], [40]. Simultaneously, societal demand for other ecosystem services provided by regulated rivers is increasing, creating a need for impact assessment methodologies. Against this background, our framework could be used to evaluate the consequences of intra-day power market balancing for flow conditions in regulated river systems and for ecosystem services.

\subsection{Limitations of the framework}

Our framework is flexible and uses open-access data from power markets, but also has some limitations. One is that estimation of LTR or natural flow adds uncertainty to the methodology. In this work, we based the calculation on scaled flow, which allowed us to use the definition of natural flow for developing the LTR for simulating water balance and calculating PMI and SER. The best option for setting LTR is to base it on measured hourly flow regime upstream of the hydropower plant. However, such time series data are not available for most rivers, because flow upstream is affected by other dams and by water consumption by other users. Moreover, measurements made at different distances upstream are not comparable, due to mid-basin contributions to flow [41]. In our flow scaling approach, the mean magnitude of flow in Eqs. (12) and (13) is the same, and only flow regime and variations differ. To overcome the lack of data (lack of measurements or upstream regulation), we used the flow dataset for a comparable unregulated river. Another limitation is lack of availability of hourly discharge data on regulated river systems, as such information is not often available from open-access data sources or even at authority level. When applying the framework to other regions, local datasets on the power market and river system should always be used. In this study we used Nordic power market data sources, but the energy supply and demand conditions for UTR can vary annually and regionally. The LTR (natural river flow) also varies for different river systems and may be affected especially by a changing climate [42].

Full compliance with the UTR strategy is highly unlikely, due to economic and site topography limitations. Installing very large hydropower capacity (e.g. 750\% of HPS) could provide flexible conditions for regulation according to UTR, but it would not work at full capacity throughout the year, so it would not be an economically feasible option. Here the selected UTR was based on the power market, although some other flow release value, e.g. one yielding more revenue, could be used as the upper threshold. For example, all water could be released during a shorter period, such as one hour, one day, one month, or during some high-price hours per day. However, these forms of release would lead to flow being cut in periods with low energy prices, which would exert considerable impacts on downstream ecosystems. In addition, such a release policy would not be fully economical, as larger and more flexible hydropower and reservoir capacity would be needed to save water and release it during the desired period, while the system (and the investment) would be useless for the rest of the time. For example, based on our case study, releasing for 1, 3, 6, 9, 12 and 18 hours per day would need a hydropower capacity of $1428 \%, 753 \%, 502 \%, 264 \%, 184 \%$ and $141 \%$ of HPS, respectively. The effects of releasing water in shorter periods 
within days (e.g. 1, 3, 6, 12 and 18 hours per day) on UTR (outflow to river) during high-price hours are demonstrated in Supplementary Material, using values based on the power market in 2017. In contrast, applying UTR allocates some flow to all hours of the year, while considering variations in energy prices, thus guaranteeing flow in the lower part of river throughout the entire year.

\section{Conclusions}

We present a framework for evaluating the coupled effects of the power market and sub-daily regulation practices on river regime, as a novel tool for sustainable river management. An increasing share of renewable energy sources (mainly wind and solar) and distributed energy production is driving regulated river systems towards higher intraday flow variations and hydropeaking and new methodologies to evaluate changes and impacts of this development on river ecohydrology are needed. Here, we applied a theoretical regulation plan, together with a scenario-based approach incorporating key constraints, to maximise the flexible nature of hydropower generation and to meet erratic energy supply-demand situations. Water release plans were designed for varying reservoir size, hydropower capacity, natural inflow and energy prices. Applying various criteria, a set of coefficients based on hourly energy prices was calculated to allocate an upper threshold release from the hydropower plant based on the power market. Two simple metrics, power market impact and system efficiency ratio, were also developed to quantify altered flow regime under proposed or actual regulation practices, which can help policymakers decide on optimum regulation practices.

The major advantage of our method is that each river is compared with its natural dimensioned flow as lower threshold releaseand the regional power market demand is considered the higher threshold release (demand). This makes each river system unique, with a quantified impact varying between 0 and 1 , which enables comparison of different river systems. The method could also be applied to estimate the consequences of future power market development and associated demands on regulated river systems. In a time of rapidly changing renewable energy market, our method helps find a balance between maintaining healthy riverine ecological status and economically exploiting the flexibility of hydropower.

\section{Acknowledgements}

This study was funded by Maj- and Tor Nessling foundation (Grant No. 201800109). Writing was supported by the BioWater project, Nordic Center of Excellence, funded by NordForsk (Project Number 82263) and by the Swedish Strategic Research Project STand UP for Energy.

\section{References}

[1] Heard BP, Brook BW, Wigley TML, Bradshaw CJA. Burden of proof: A comprehensive review of the feasibility of $100 \%$ renewable-electricity systems. Renewable Sustainable Energy Rev 2017; 76:1122-33.

[2] Armstrong R, Wolfram C, De Jong K, Gross R, Lewis NS, Boardman B, Ragauskas A, Ehrhardt-Martinez K, Crabtree G, Ramana M. The frontiers of energy. Nature Energy 2016; 1.

[3] Mitchell C. Momentum is increasing towards a flexible electricity system based on renewables. Nature Energy 2016; 1.

[4] Graabak I, Korpås M. Balancing of variable wind and solar production in Continental Europe with Nordic hydropower - a review of simulation studies. Energy Procedia 2016; 87:91-9. 
[5] Yang W, Norrlund P, Saarinen L, Witt A, Smith B, Yang J, Lundin, U. Burden on hydropower units for shortterm balancing of renewable power systems. Nat Commun 2018; 9.

[6] Chang MK, Eichman JD, Mueller F, Samuelsen S. Buffering intermittent renewable power with hydroelectric generation: A case study in California. Appl Energy 2013; 112:1-11.

[7] Gaudard L, Romerio F. The future of hydropower in Europe: Interconnecting climate, markets and policies. Environ Sci Policy 2014; 37:172-81.

[8] Patro ER, De Michele C, Avanzi F. Future perspectives of run-of-the-river hydropower and the impact of glaciers' shrinkage: The case of Italian Alps. Appl Energy 2018; 231:699-713.

[9] Boehlert B, Strzepek KM, Gebretsadik Y, Swanson R, McCluskey A, Neumann JE McFarland, J, Martinich, J. Climate change impacts and greenhouse gas mitigation effects on U.S. hydropower generation. Appl Energy 2016; 183:1511-9.

[10] Gaete-Morales C, Gallego-Schmid A, Stamford L, Azapagic A. A novel framework for development and optimisation of future electricity scenarios with high penetration of renewables and storage. Appl Energy 2019:1657-72.

[11] Torabi Haghighi A, Kløve B. Development of a general river regime index (RRI) for intra-annual flow variation based on the unit river concept and flow variation end-points. J Hydrol 2013; 503:169-77.

[12] Richter BD, Baumgartner JV, Powell J, Braun DP. A Method for Assessing Hydrologic Alteration within Ecosystems. Conservation Biology 1996; 10:1163-74.

[13] Bevelhimer MS, McManamay RA, O'Connor B. Characterizing Sub-Daily Flow Regimes: Implications of Hydrologic Resolution on Ecohydrology Studies. River Res Appl 2015; 31:867-79.

[14] Arheimer B, Donnelly C, Lindström G. Regulation of snow-fed rivers affects flow regimes more than climate change. Nat Commun 2017; 8.

[15] Torabi Haghighi A, Darabi H, Shahedi K, Solaimani K, Kløve B. A Scenario-Based Approach for Assessing the Hydrological Impacts of Land Use and Climate Change in the Marboreh Watershed, Iran. Environ Model Assess 2019.

[16] Fazel N, Torabi Haghighi A, Kløve B. Analysis of land use and climate change impacts by comparing river flow records for headwaters and lowland reaches. Global Planet Change 2017; 158:47-56.

[17] Pirnia A, Darabi H, Choubin B, Omidvar E, Onyutha C, Haghighi AT. Contribution of climatic variability and human activities to stream flow changes in the Haraz River basin, northern Iran. Journal of Hydroenvironment Research 2019.

[18] Ashraf FB, Torabi Haghighi A, Marttila H, Kløve B. Assessing impacts of climate change and river regulation on flow regimes in cold climate: A study of a pristine and a regulated river in the sub-arctic setting of Northern Europe. J Hydrol 2016; 542:410-22.

[19] Carolli M, Vanzo D, Siviglia A, Zolezzi G, Bruno MC, Alfredsen K. A simple procedure for the assessment of hydropeaking flow alterations applied to several European streams. Aquatic Sci 2015; 77:639-53. 
[20] Ashraf FB, Haghighi AT, Riml J, Alfredsen K, Koskela JJ, Kløve B, Marttila, H. Changes in short term river flow regulation and hydropeaking in Nordic rivers. Sci Rep 2018; 8.

[21] Harnish RA, Sharma R, McMichael GA, Langshaw RB, Pearsons TN. Effect of hydroelectric dam operations on the freshwater productivity of a Columbia river fall Chinook salmon population. Can J Fish Aquatic Sci 2014; 71:602-15.

[22] Casas-Mulet R, Saltveit SJ, Alfredsen KT. Hydrological and thermal effects of hydropeaking on early life stages of salmonids: A modelling approach for implementing mitigation strategies. Sci Total Environ 2016; 573:1660-72.

[23] Chen Q, Zhang X, Chen Y, Li Q, Qiu L, Liu M. Downstream effects of a hydropeaking dam on ecohydrological conditions at subdaily to monthly time scales. Ecol Eng 2015; 77:40-50.

[24] Krause F. River Management. Technological Challenge or Conceptual Illusion? Salmon Weirs and Hydroelectric Dams on the Kemi River in Northern Finland. Schmidt M, Onyango V, Palekhov D 2005:229-48.

[25] Anderson D, Moggridge H, Warren P, Shucksmith J. The impacts of 'run-of-river' hydropower on the physical and ecological condition of rivers. Water Environ J 2015; 29:268-76.

[26] Nilsson C, Reidy CA, Dynesius M, Revenga C. Fragmentation and flow regulation of the world's large river systems. Science 2005; 308:405-8.

[27] Torabi Haghighi A, Marttila H, Kløve B. Development of a new index to assess river regime impacts after dam construction. Global Planet Change 2014;122: 186-96.

[28] Mihalicz JE, Jardine TD, Baulch HM, Phillips ID. Seasonal effects of a hydropeaking dam on a downstream benthic macroinvertebrate community. River Res Appl 2019; 35:714-24.

[29] Sundt-Hansen LE, Hedger RD, Ugedal O, Diserud OH, Finstad AG, Sauterleute JF, Tøfte L, Alfredsen K, Forseth T. Modelling climate change effects on Atlantic salmon: Implications for mitigation in regulated rivers. Sci Total Environ 2018;631-632:1005-17.

[30] Juárez A, Adeva-Bustos A, Alfredsen K, Dønnum BO. Performance of a two-dimensional hydraulic model for the evaluation of stranding areas and characterization of rapid fluctuations in hydropeaking rivers. Water $2019 ; 11$.

[31] Alnæs EN, Grøndahl RB, Fleten S-, Boomsma TK. Insights from actual day-ahead bidding of hydropower. Int J Sustain Energy Plann Manage 2015; 7:37-58.

[32] Aasgård EK, Fleten S-, Kaut M, Midthun K, Perez-Valdes GA. Hydropower bidding in a multi-market setting. Energy Syst 2019; 10:543-65.

[33] Vardanyan Y, Hesamzadeh MR. The coordinated bidding of a hydropower producer in three-settlement markets with time-dependent risk measure. Electr Power Syst Res 2017; 151:40-58.

[34] Raynaud D, Hingray B, François B, Creutin JD. Energy droughts from variable renewable energy sources in European climates. Renew Energy 2018; 125:578-89. 
[35] Mileva A, Johnston J, Nelson JH, Kammen DM. Power system balancing for deep decarbonization of the electricity sector. Appl Energy 2016; 162:1001-9.

[36] USBR. Design of small dams. Third ed. Washington: UNITED STATES DEPARTMENT OF THE INTERIOR BUREAU OF RECLAMATION, 1987.

[37] Mustonen K-, Mykrä H, Marttila H, Haghighi AT, Kløve B, Aroviita J, Veijalainen N, Sipple K. Muotka T. Defining the natural flow regimes of boreal rivers: Relationship with benthic macroinvertebrate communities. Freshwater Sci 2016;35:559-72.

[38] Wilson MA, Carpenter SR. Economic valuation of freshwater ecosystem services in the United States: 19711997. Ecol Appl 1999;9:772-83.

[39] Graabak I, Warland L. A carbon neutral power system in the Nordic region in 2050. SINTEF Energy Research, Trondheim, Norway, TR A 2014; 7365.

[40] Sauterleute J, Wolfgang O, Graabak I. Scenarios for large-scale balancing and storage from Norwegian hydropower. Water Resour 2015; 2015:02-26.

[41] Torabi Haghighi A, Kløve B. Development of monthly optimal flow regimes for allocated environmental flow considering natural flow regimes and several surface water protection targets. Ecol Eng 2015; 82:390-9.

[42] Palmer MA, Reidy Liermann CA, Nilsson C, Flörke M, Alcamo J, Lake PS, Bond N. Climate change and the world's river basins: Anticipating management options. Frontiers Ecol Envir 2008; 6:81-9. 